\title{
EVALUATION OF AN ASPHALT MIXTURE CONTAINING A HIGH CONTENT OF RECLAIMED ASPHALT AND DIFFERENT CRUMB RUBBER MODIFIED BINDERS
}

\author{
Majda BELHAJ ${ }^{1 *}$, Pavla VACKOVÁ ${ }^{1}$, Jan VALENTIN ${ }^{1}$
}

\begin{abstract}
Recently, environmental concerns have become a primary driving force in most countries and industries dealing with natural resources. As a part of this category, asphalt pavement industry is trying to implement more green and sustainable features in its products, while maintaining the mechanical and performance-based properties of the resulting asphalt mixtures. Among potential recycled materials, vehicle tires and aged asphalt pavement have been demonstrated to show economic, ecological, and behavioral improvements in the mixtures. However, mixtures with a high content of reclaimed asphalt (RA) and crumb rubber present some limitations. Therefore, using another group of additives, i.e., a warm mix asphalt (WMA) additive, has been considered. The presented paper investigates the use of an elevated content of RA with different crumb rubber modified binders and (in some mixtures) a warm mix additive in an asphalt concrete (AC) binder mix. Regular empirical tests have been conducted and more advanced performance or functional characteristics, i.e., stiffness, thermal induced cracking, resistance to permanent deformation, complex modulus have been determined and evaluated. Selected results are presented in the paper.
\end{abstract}

\section{Address}

1 Faculty of Civil Engineering, Czech Technical University in Prague, Czech Republic

* Corresponding author: majda.belhaj@fsv.cvut.cz

\section{Key words}

- Reclaimed Asphalt,

- Crumb rubber modified binder,

- Crumb rubber.

\section{INTRODUCTION}

The use of reclaimed asphalt (RA) is a well-established and common practice in pavement engineering, which can be seen in most developed countries. The use of recycled materials as an important aspect of sustainability in civil engineering has resulted in considerable savings in raw material resources, energy, and costs. Several studies have been performed in order to evaluate the feasibility of incorporating RA in new asphalt mixtures.
Another recyclable material available worldwide in huge amounts is rubber, mainly recycled rubber derived from old tires. The automobile industry (car use) in today's industrial world is producing enormous amounts of waste tires all over the world. In order to address this growth and face the massive and emerging pile of tires in the current century, it is essential to think about reusing and recycling used tires, which is a task country have been trying to solve intensively for more than 40 years. Additionally, the vast majority of these tires that are landfilled or burned, e.g., 
in cement kilns, have been considered as a serious threat that can dramatically impact the environment and eventually pose a serious health hazard to human life (e.g. the annihilation of pests or fauna, fire risks, etc.) (Farshad Saberi et al., 2017). To that end, the use of recycled tires has been evolving in several industries such as tire - derived fuels or pyrolytic oils, civil engineering applications (embankments, septic system drain fields, subgrade fills, in-fills for outdoor sport grounds or playgrounds etc.), and crumb rubber applications (Mohammad et al., 2013). Quite commonly, crumb rubber is used as a modifier in the construction of asphalt pavements. Crumb rubber is one of the major available material, and it can be used to improve the performance of bituminous mixtures (Mohammad et al., 2013). It is usually employed in asphalt mixtures in two different mixing processes: (i) a "dry process" in which the crumb rubber is initially mixed with aggregates and then with a bituminous binder, usually using larger crumbs, and (ii) a "wet process" in which the crumb rubber or rubber powder is initially mixed with a bituminous binder, such as various chemical modifiers in a modified polymer bitumen and then added to aggregates. There are also hybrid systems, where the rubber is initially mixed in higher contents with the bitumen creating a concentrate; this composite material is cooled down, milled or ground and then used directly in mixing plants together with aggregates and paving grade bitumen.

In recent research projects similar to the experimental study presented in this paper, the bituminous binders were modified by the crumb rubber ("wet process"), which was then used for asphalt mixture productions (the wet process method was used). Therefore, the binder is called as crumb rubber modified bitumen (CRMB) (Singh et al., 2017).

The aim of this experimental study was to combine both of the phenomena, i.e., the use of elevated RA content and crumb rubber. The use of these recycled materials has some limitations e.g. decreased workability, the necessity of increased mixing and compaction temperatures, the hardening of the aged binder, etc. (Xiao et al., 2009). For these reasons, another additive warm mix asphalt (WMA) was used and studied. Due to the global warming issues and the increasing cost of energy, several researchers have been developing solutions to reduce mixing temperatures such as applying warm mix asphalt (WMA) additives, i.e., chemical or organic additives on wax bases (Rodríguez-Alloza et al., 2013). These additives have the potential to reduce the mixing temperature, usually by lowering the viscosity of the binder (Behroozikhah and Morafa, 2017). In that study, the Fischer-Tropsch based wax or polyethylene wax was used more in order to improve the workability than to reduce the compaction temperature. As it will be shown below, the temperature was decreased only by $10{ }^{\circ} \mathrm{C}$ (even though there is a potential for additional decreases).

In summary, the objective of this study was to evaluate the laboratory performance of asphalt mixtures containing elevated amounts of RA, crumb rubber and in some variants, a warm mix asphalt additive. This was accomplished through an evaluation of properties such as stiffness, indirect tensile strength (ITS) and moisture susceptibility, resilient modulus, rutting resistance, and crack propagation resistance.

\section{ASSESSED ASPHALT MIXTURES}

In this research study $\mathrm{AC}_{\text {bin }} 16$ with $40 \%$ reclaimed asphalt (RA) and $\mathrm{AC}_{\text {bin }} 22$ with $30 \% \mathrm{RA}$ were manufactured and evaluat- ed. This study covers 6 versus 5 asphalt mix variants containing different kinds of bituminous binders. The study covers:

- unmodified paving grade bitumen - 50/70 and 70/100;

- polymer modified binder PMB 25/55-60;

- high viscous crumb rubber modified bitumen CRMB 25/55$60 \mathrm{~V}$ (ready-to-use produced by a blender); - crumb rubber modified binder based on paving grade bitumen 50/70 and $15 \%$ of crumb rubber (CR) (laboratory made which can be considered as a terminal blend).

The use of the unmodified bitumen 50/70 and 70/100 and the polymer modified binder PMB 25/55-60 in this study were for comparative reasons. They were set as referential bitumen to which the effect of the crumb rubber will be evaluated.

The CRMBs used in this study were either an industrial bitumen or were prepared in a laboratory. The crumb rubber modified bitumen CRMB 25/55-60 V is a ready-to-use and unique type of bitumen whose properties are improved by the incorporation of a high content of crumb rubber ( $>15 \%$ by mass of the bitumen). According to the manufacturer, this kind of binder should be a durable, dependable and economical solution for rutting, ravelling undulation, shoving and pothole solutions compared to the polymer modified bitumen. For the laboratory-made bitumen, a "DE11" warm mix additives was used. The "DE11" additive is a polyethylene wax compound and an ecological modifier of bitumen. It was dosed in $3 \%$ of the binder. The compaction temperature of the mixtures with warm-asphalt additives was lowered from $160{ }^{\circ} \mathrm{C}$ to $150{ }^{\circ} \mathrm{C}$.

\section{TESTING OF ASPHALT MIXTURES}

The aim of the research study was to compare the properties of the asphalt mixtures with RA and different kinds of modified binders. To evaluate the effects of the variants tested, the following tests were performed and evaluated:

- volumetric characteristics (according to EN 12697-5, EN 12697-6, EN 12697-8);

- water and water+freeze susceptibility (according to

EN 12697-12 and AASHTO T283-3)

- stiffness (according to EN 12697-26, method IT-CY) at test temperatures of $0^{\circ} \mathrm{C}, 15^{\circ} \mathrm{C}$, and $27^{\circ} \mathrm{C}$;

- fracture toughness determined by the SCB test (according to a modified Czech method proceeding from EN 12697-44) performed on $100 \mathrm{~mm}$ diameter semi-cylindrical specimens with a loading rate of $2.5 \mathrm{~mm} / \mathrm{min}$;

- resistance to permanent deformation (according to EN 1269722) in a small test device using an air bath at a test temperature of $50^{\circ} \mathrm{C}$.

- dynamic modulus determined by a 4-point bending test (according to EN 12697-26) at test temperatures of $0^{\circ} \mathrm{C}, 10^{\circ} \mathrm{C}$, $20^{\circ} \mathrm{C}$, and $30^{\circ} \mathrm{C}$.

\subsection{Volumetric characteristics}

The volumetric characteristics were compared with the limits required by the national product standard CSN 73 6121. The standard limit and threshold values for the product type testing are highlighted in Figs. 1 and 2. The volumetric characteristics were determined on test specimens compacted according to EN 


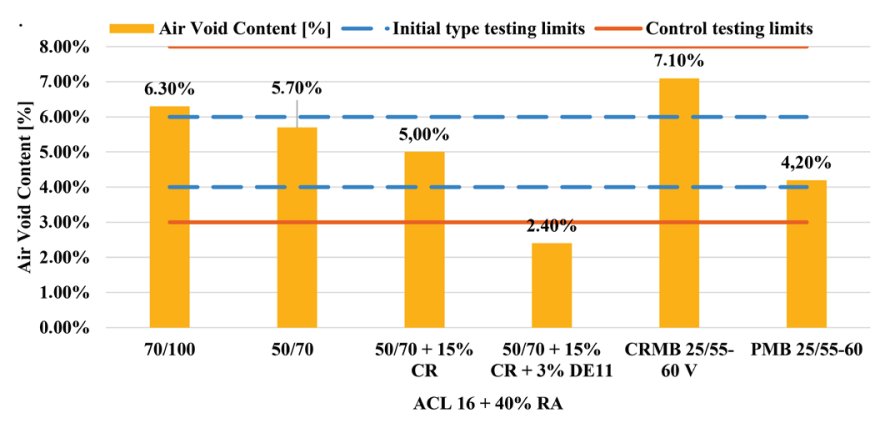

Fig. 1 Air void content for the $A C_{b i n} 16+40 \% R A$

1269730 at temperatures of $150^{\circ} \mathrm{C}$ (for the paving grade binder and $\mathrm{CRMB}$ variants with the warm mix additive) and $160^{\circ} \mathrm{C}$ (for CRMB without additives).

The air void content was lowered when the modified binders were used in comparison to the referential mixture with 50/70 except with the binder CRMB V, which showed a significant increase of $1.4 \%$. This increase was probably caused by the elevated amount of the crumb rubber in the modified binder $(>15 \%$ by mass). When the WMA additive was used, the mixture exceeded the lower limit. It showed that potential for a further decrease of the manufacturing and compaction temperatures but was not the aim of the project.

An unforeseen result seen for the mix variant with 70/100. It was expected that the use of a softer bitumen would lower the air void contents, but this did not occur, and the air void content increased by almost $1 \%$.

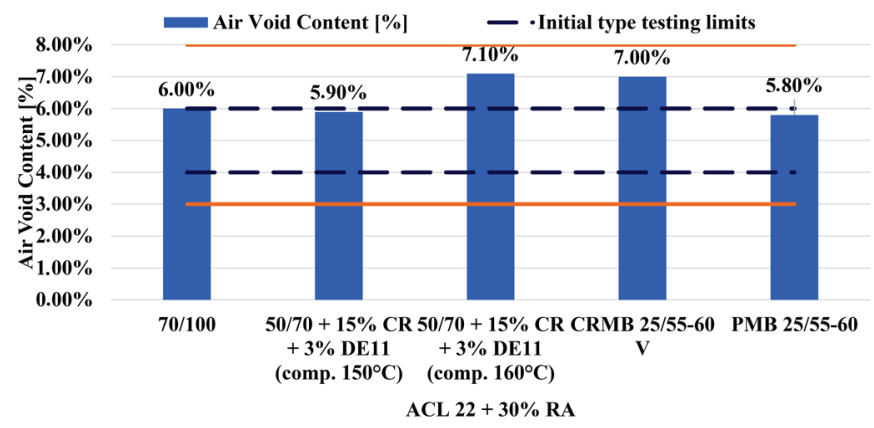

Fig. 2 Air void content for the $A C_{\text {bin }} 22+30 \% R A$

Fig. 2 shows that the addition of the WMA additives and manufacturing the mixture at a lower compaction temperature $\left(150^{\circ} \mathrm{C}\right)$ showed improved results compared to the typical laboratory compaction temperature $\left(160^{\circ} \mathrm{C}\right)$ by more than $1 \%$ in the air void content. This also showed very close results to the mixture with the PMB. Therefore, it could be an alternative concerning this characteristic.

\subsection{Stiffness}

The stiffness modulus was determined on Marshall test specimens by the IT-CY test method (non-destructive repeated indirect tensile stress test) according to EN 1269726 at three selected test temperatures: $0^{\circ} \mathrm{C}, 15^{\circ} \mathrm{C}$, and $27^{\circ} \mathrm{C}$, which are common for countries like the Czech Republic and have traditionally been tested for several decades.
The use of the modified binders improved the stiffness for all the variants, only the mixture with the polyethylene wax (DE11) showed worse parameters. Thus, the resistance to the appearance of damage due to traffic loads and the environmental conditions was not improved.

Further, the thermal susceptibility was calculated as a ratio of the stiffness modulus determined at temperatures of $0^{\circ} \mathrm{C}$ and $27^{\circ} \mathrm{C}$. The lower the thermal susceptibility, the less sensitive to thermal changes the asphalt mix is with respect to its deformation characteristics. The lower the value, the better the mix will resist climatic changes. The thermal susceptibility is very similar for all the variants, but it is the lowest for the mix variant with $15 \%$ crumb rubber (CR). The WMA additive used not only decreased the stiffness, but also increased the thermal susceptibility.

The highest values of the thermal susceptibility were reached by both the polymer-modified bitumen CRMB 25/5560V and PMB 25/55-60 respectively due to the high viscosity of these binders.

For the mixture with the maximum aggregate size of $22 \mathrm{~mm}$, the results appear to be different. All the modified variants were balanced at temperatures of $0^{\circ} \mathrm{C}$ and $15^{\circ} \mathrm{C}$. The mixture with CRMB 25/55-60 V evinces the best stiffness modulus and the lowest thermal susceptibility results. The CRMB V binder improved the resistance to the appearance of damage due to traffic loads and the environmental conditions of the mixture. It could therefore have been a good alternative for a traditional PMB following this performance characteristic.
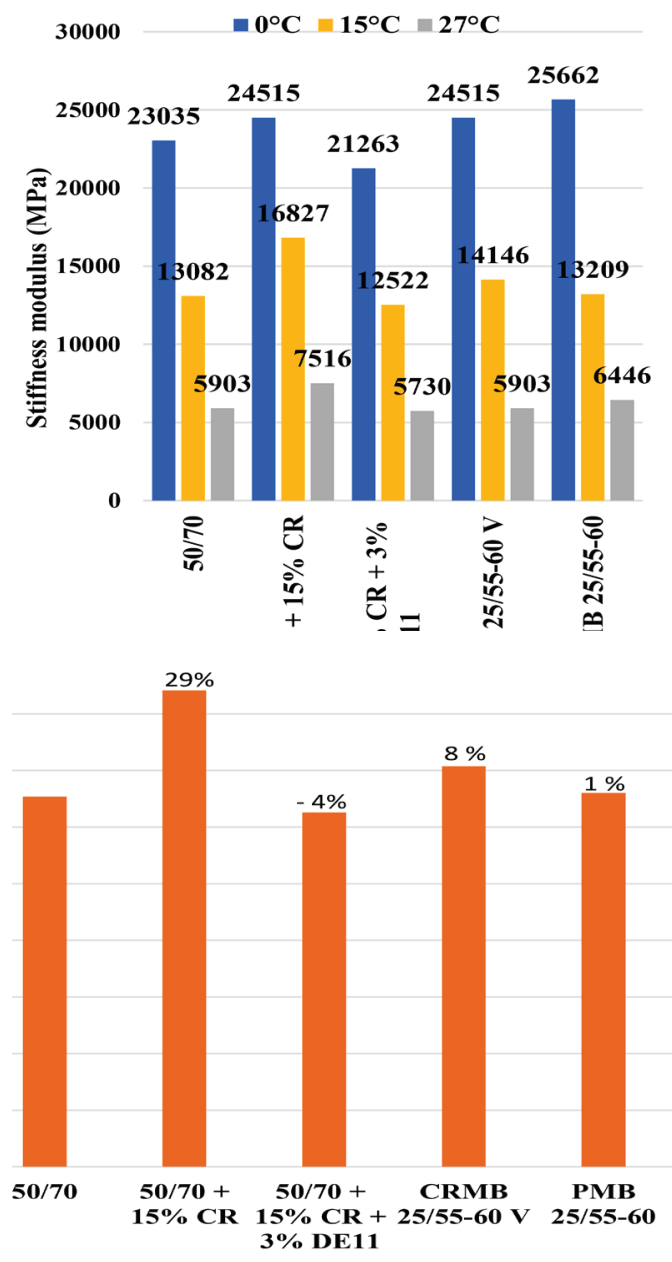

Fig. 3 Stiffness modulus of ACbin 16+ mixtures with $40 \%$ RA and CR application 


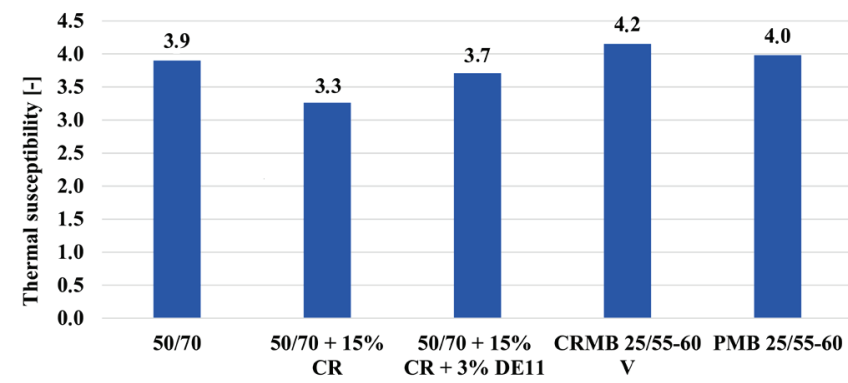

Fig. 4 Thermal susceptibility of ACbin 16+ mixtures with $40 \%$ RA and CR application

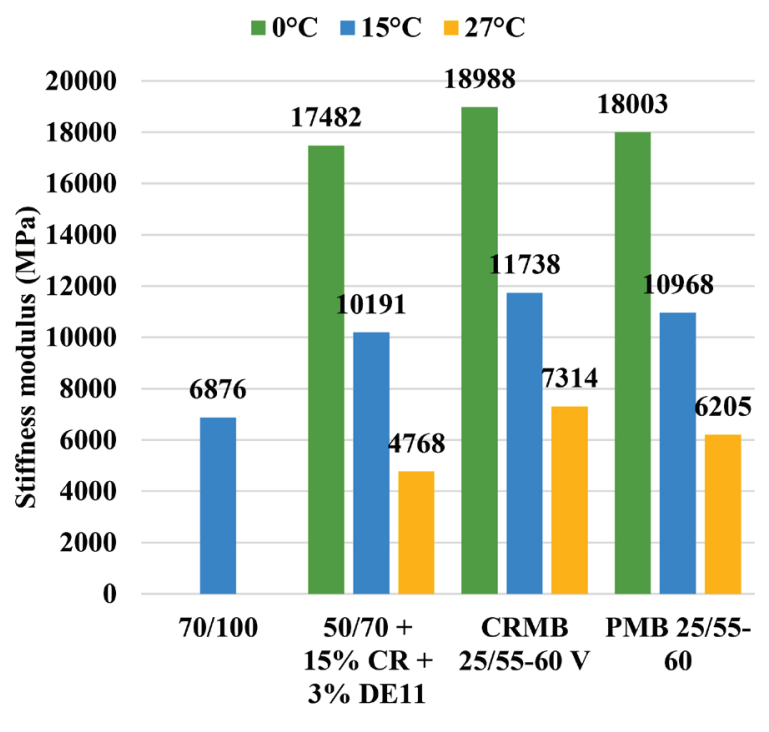

Fig. 5 Stiffness modulus of $A C_{b i n} 22$ mixtures with $30 \% R A$ and $C R$ application

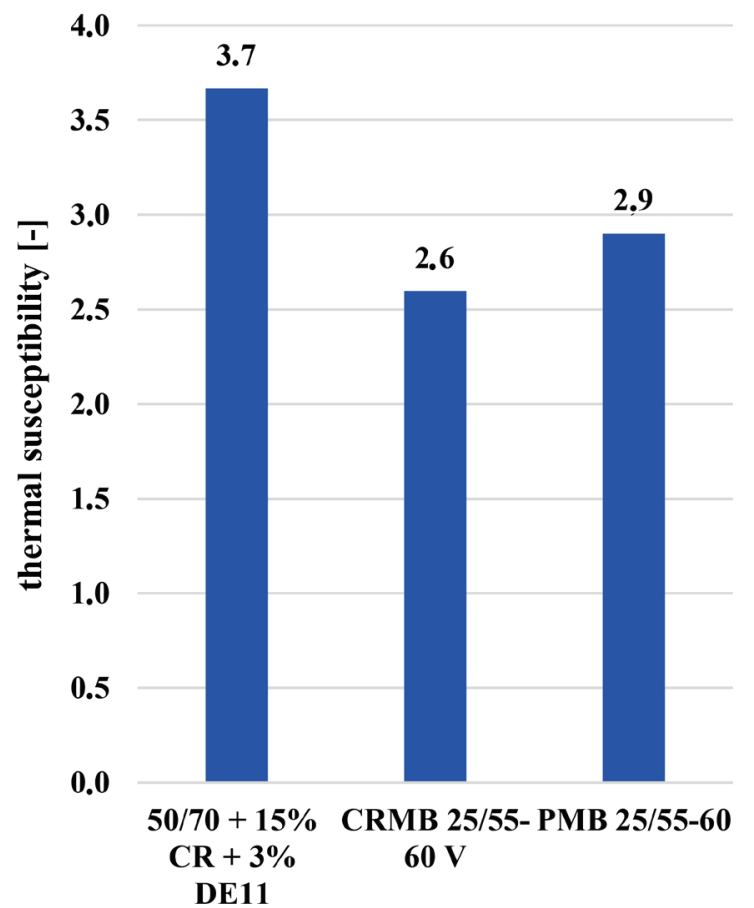

Fig. 6 Thermal susceptibility of $A C_{\text {bin }} 22$ mixtures with $30 \% R A$ and CR application

\subsection{Water and water+freeze susceptibility}

The determination of the water and frost resistance was performed in accordance with EN 12697-12 and AASHTO T 283-3 (a modified procedure used by the CTU in Prague for more than 7 years). The U.S. testing method was included to extend the European procedure by a freezing cycle which we believe provides some additional information about the durability of the asphalt.

For each mixture a set of 9 Marshall test specimens was compacted by $2 \times 25$ blows from an impact compactor (EN 12697-30). These specimens were divided into three groups, where each group was subjected to another conditioning process. The "dry" specimens were stored dry at room temperature and at a normal relative humidity. The "EN" specimens were subjected to a saturation procedure according to EN 12697-12, when the specimens were saturated and stored in a water bath at $40^{\circ} \mathrm{C}$ for 72 hours. The last set of so called "AASHTO" specimens was saturated and stored in a plastic bag for 18 hours in a freezer at $-18{ }^{\circ} \mathrm{C}$ and then stored in a water bath at $60^{\circ} \mathrm{C}$ for 24 hours. The indirect tensile

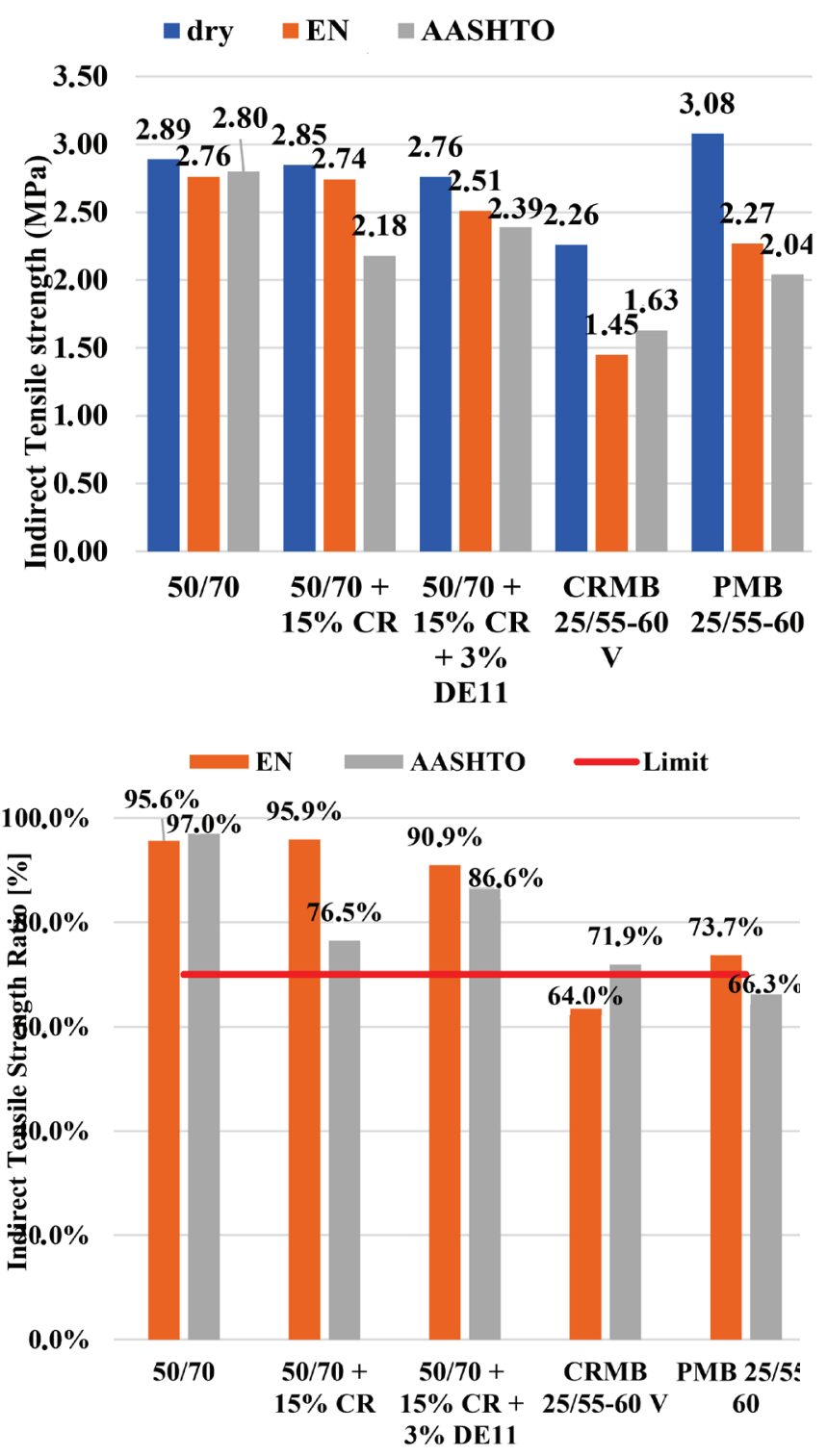

Fig. 7 Indirect tensile strength (ITS) (left) and ITS ratio (right) of $A C_{b i n} 16+$ mixture with a $40 \% R A$ and $C R$ application 


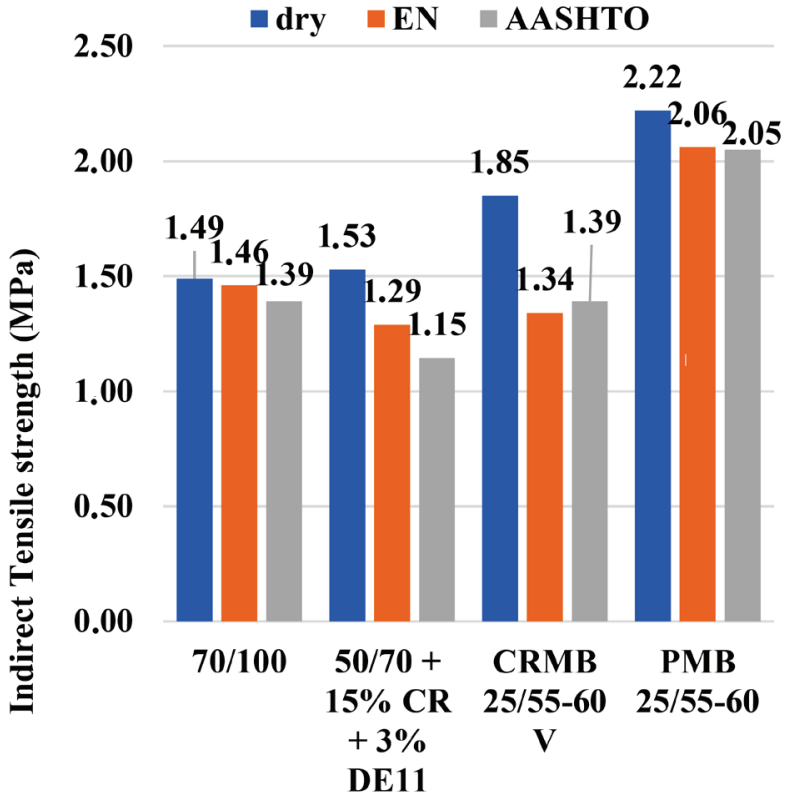

ACL $22+30 \%$ RA

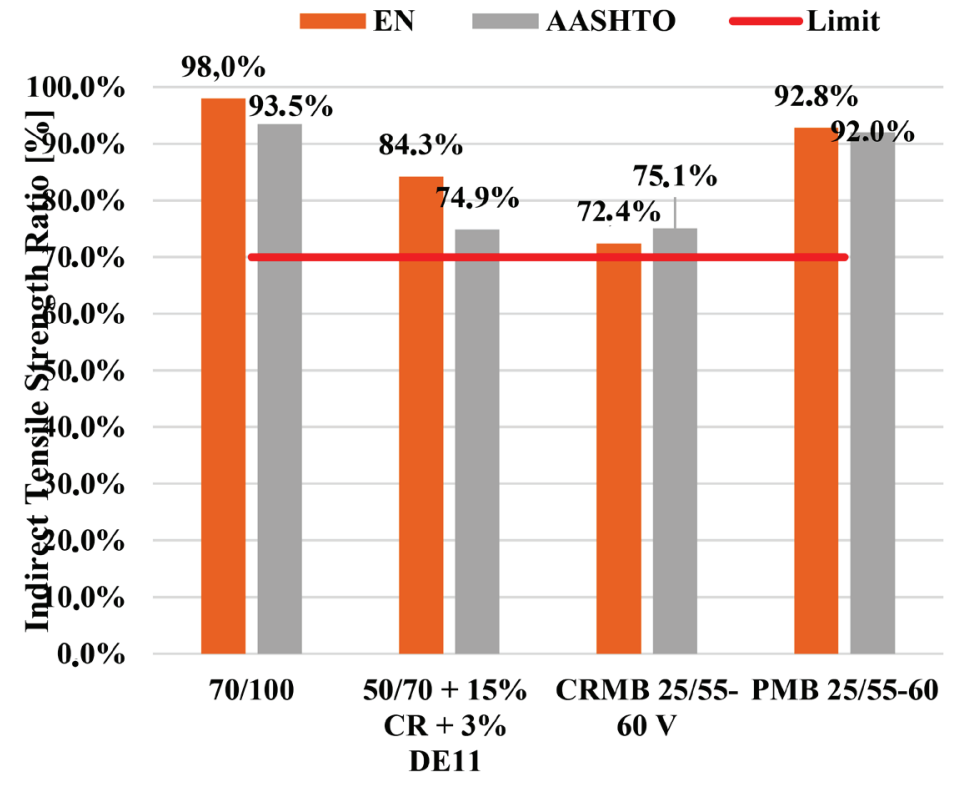

ACL $22+30 \%$ RA

Fig. 8 Indirect tensile strength (ITS) (left) and ITS ratio (right) of ACbin $22+$ mix with $30 \%$ RA and CR application

strength test was performed for all of the specimens at a temperature of $15^{\circ} \mathrm{C}$ according to EN 12697-23.

As shown in the Fig. 7, the ITS $_{\text {dry }}$ of the variants with $15 \%$ crumb rubber showed very similar values compared to the referential variant with paving grade 50/70. The PMB binder showed the highest values, while the variants with CRBM V, showed the lowest. The decrease in ITS of the CRMB V variants is slightly unexpected, because the stiffness modulus showed quite good strength.

According to the "EN" procedure, the variant with $15 \% \mathrm{CR}$ also showed the highest indirect tensile strength ratio, thus the best water resistance compared to the 50/70 binder. However, the latter showed a lower ratio according to the "AASHTO" procedure. Even though the mixture with $15 \% \mathrm{CR}+3 \%$ DE11 showed lesser improvement in water resistance compared to the variant with $15 \%$ $\mathrm{CR}$, it however showed the better effects on the cracking resistance of the mixture and the frost influence on the specimen.

The very poor results of the ITSR were reached by the mixtures with PMB (surprising and hard to interpret) and CRMB V (indicating one of the typically weak aspects of CRMB applications) binders. The ITSR $_{\mathrm{EN}}$ limit determined by the CSN 736121 standard for asphalt mixture $\mathrm{AC}_{\text {bin }} 16+$ set at $70 \%$ was exceeded by the variant with PMB only mildly, and CRMB V variant did not overstep it.

For the $\mathrm{AC}_{\mathrm{bin}} 22$, the results again show slightly different results. The best of which were again reached by the mixtures with a PMB binder, but this variant showed much better ITSR results. Although the ITS of the variant with CRMB V increased in comparison to referential value, the ITSR was very low.

\subsection{Resistance to crack propagation}

The resistance to crack propagation was tested in accordance with EN 12697-44:2011. The essence of the test is a three-point bending of semi-circular test specimens with a defined notch in the middle of the bottom specimen surface. The testing process was modified with respect to conditions suitable for a Czech lab- oratory environment. Contrary to the standard procedure, a cylindrical test specimens compacted by an impact compactor with a diameter of $100 \mathrm{~mm}$ were used. Also, the test rate was lowered from $5 \mathrm{~mm} / \mathrm{min}$ to $2.5 \mathrm{~mm} / \mathrm{min}$. The test parameters were extended, i.e., according to the European standard, only fracture toughness is determined, but in the case of this study, fracture energies were also calculated. The energy is calculated from the load-displacement diagram as an integral of the loading curve divided by the fracture area. The fracture energy was determined in two stages, i.e., until the maximum force $\left(\mathrm{F}_{\max }\right)$ was reached and then as the total fracture energy, including the unloading part. In our opinion, using both parameters provides more information about the behavior of the asphalt mix in the range of low temperatures.

As to the test itself, it can generally be said that the higher the value of the fracture toughness, the better the resistance to thermal-induced cracking. Also, the higher the stiffness modulus is, the lower the fracture toughness usually is. However, this second rule cannot be generalized and is not always true.

The resistance to thermal-induced cracking was determined at two temperatures $0{ }^{\circ} \mathrm{C}$ and $25^{\circ} \mathrm{C}$. It appears that the fracture toughness decreases when the test temperature as well as all the strength characteristics increase. On the other hand, this does not apply to fracture energy, which is influenced not "only" by maximum force, but also more likely by the maximum strain (deformation).

According to the fracture toughness, fracture energy at the maximum force, and total fracture energy results, the mixture with CRMB V has the best resistance to thermal-induced and fatigue cracking. Surprisingly, the mix variant with the softer paving grade bitumen 70/100 did not achieve as good results as expected, which was, however, exceeded by all the mixtures tested. It is possible that this gradation of bitumen is too soft for use in such a mixture and is insufficiently stiff.

The "superaged" mixture was originally planned to be tested as a regular set of test specimens, but, coincidentally, the test specimens were extremely aged; it was therefore, decided to test them in parallel to see the impact of extreme ageing. This mix- 


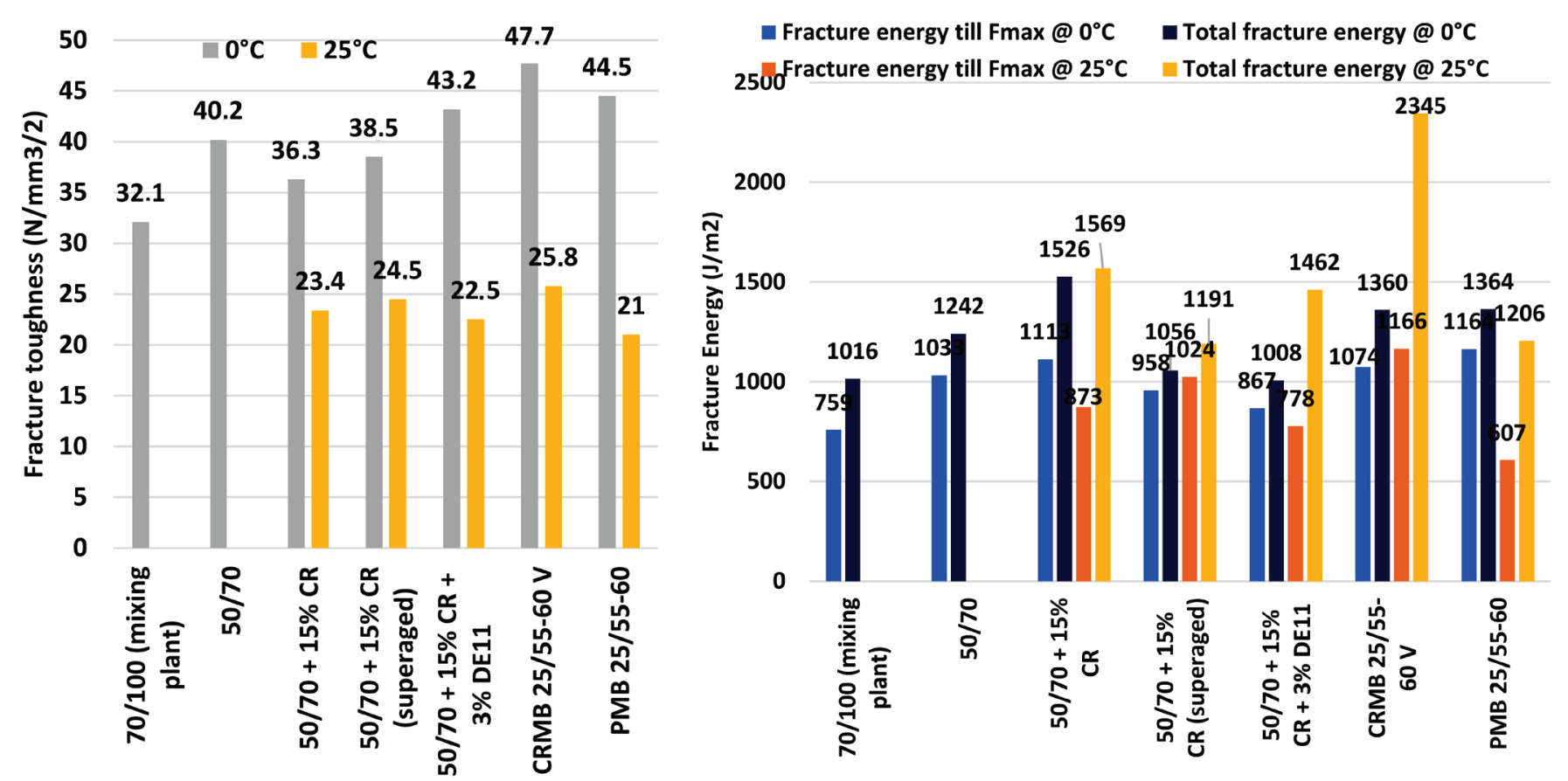

Fig. 9 Fracture toughness (left) and fracture energy (right) of the ACbin 16+ mixture with $40 \%$ RA and CR application

ture showed better results in the fracture energy results than the "unaged" one at both temperatures, which is only partly surprising and might be an example of how important it is not only to follow purely fracture toughness but also the focus on fracture energy.

From the point of view of both fracture energies (until $\mathrm{F}_{\text {max }}$ and including even the unloading part of the load displacement diagram), the best results were achieved by the variant with the $15 \%$ crumb rubber. The addition of the WMA additive in combination with the crumb rubber showed a decrease in both fracture energies; on the other hand, there was an increase in the fracture toughness. The mix variants achieved very similar values of stiffness or indirect tensile strength, but the differences in the fracture characteristics are significant.

Behavior in the low temperature range strongly depends on strength and flexibility of an asphalt mixture. From the results it is apparent that, in the case of the $\mathrm{AC}_{\mathrm{bin}} 22+$ mixture, the vari-

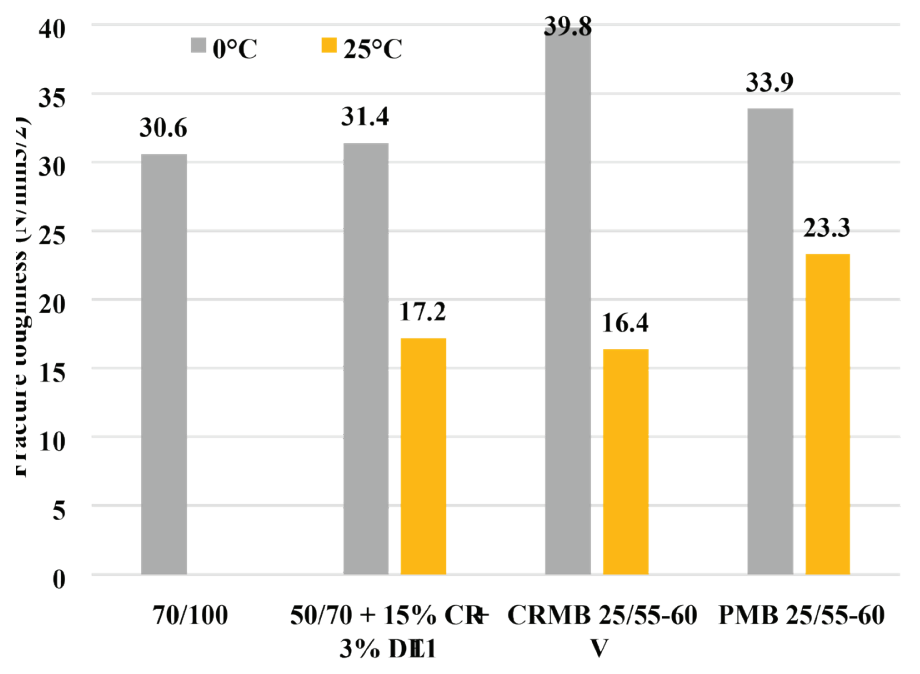

ant with the CRMB 25/55-60 V performs better than the mixtures with the WMA additive or PMB. This result was confirmed by both characteristics of the fracture energies. As for the resistance to fatigue cracking, the mixture with the PMB showed the best values.

\subsection{Resistance to permanent deformation}

The resistance to permanent deformation was determined in accordance with EN 12697-22 in a small test device using an air bath with a test temperature of $50^{\circ} \mathrm{C}$. The national requirements based on asphalt mix product standard CSN 736121 set the maximum values for the two test parameters, i.e., $\mathrm{PRD}_{\text {AIR }}$ and $\mathrm{WTS}_{\mathrm{AIR}}$. For the average rut depth $\left(\mathrm{PRD}_{\mathrm{AIR}}\right)$, the maximum value for $\mathrm{AC}_{\mathrm{bin}}$ is generally $4.0 \%$ and for the increment of rut depth $\left(\mathrm{WTS}_{\mathrm{AIR}}\right)$, the required threshold value is $0.06 \mathrm{~mm} / 10^{3}$ cycles.

- Fracture energy till Fmax @ $0^{\circ} \mathrm{C}-\mathrm{T}^{-}$tal fracture energy $@ 0^{\circ} \mathrm{C}$

- Fracture energy till Fmax @ $2^{\circ} \mathrm{C}$ Total fracture energy $@ 25^{\circ} \mathrm{C}$ 2500

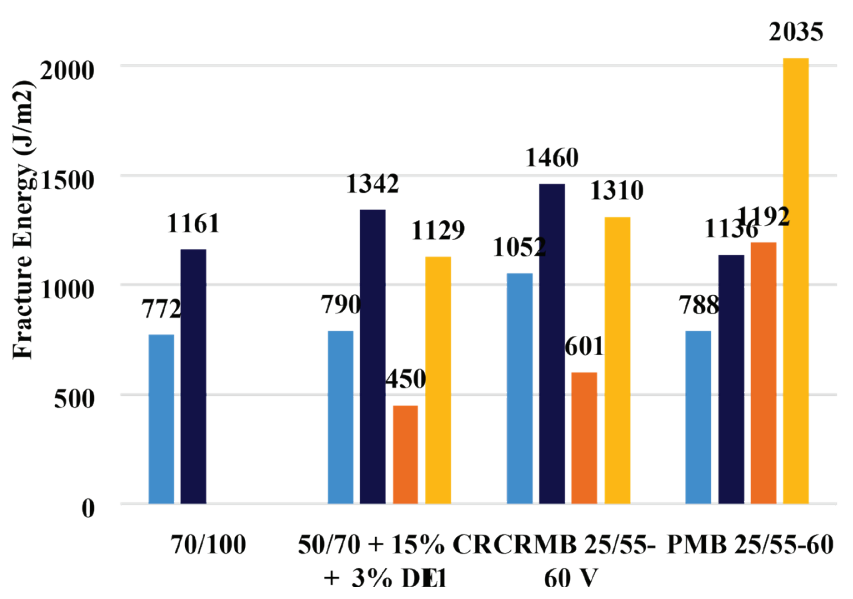

Fig. 10 Fracture toughness (left) and fracture energy (right) of the ACbin $22+$ mix with the 30\% RA and CR application 


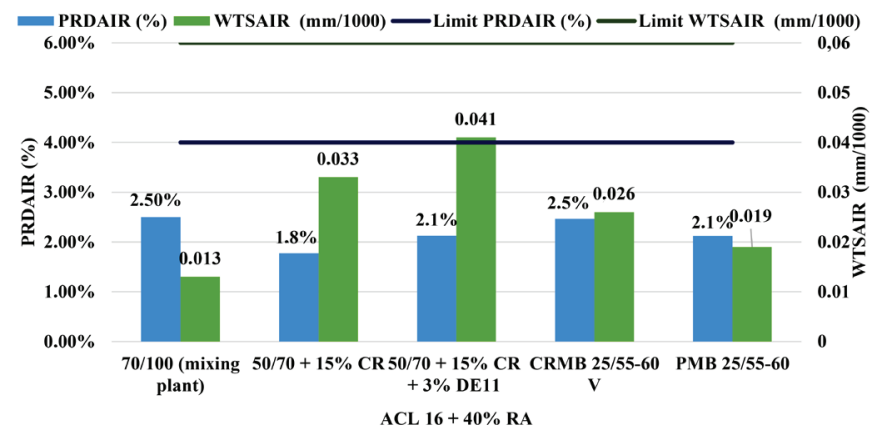

Fig. 11 Resistance to permanent deformation for the $A C_{b i n} 16+$ with $40 \% R A$

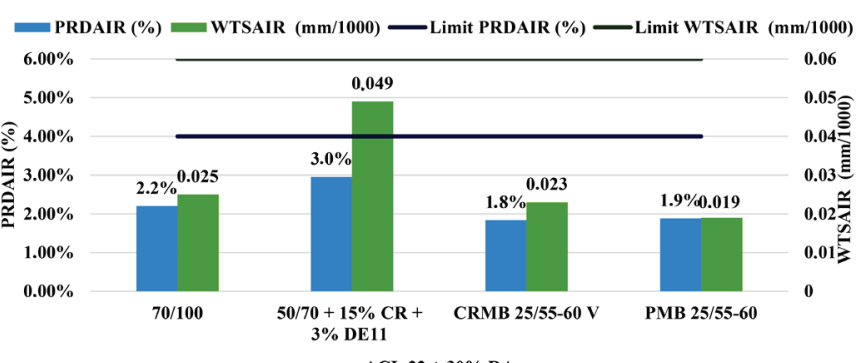

Fig. 12 Resistance to permanent deformation for the $A C_{b i n} 22+$ with $30 \% R A$

As is shown in Fig. 11, the use of the modified binders improves the average rut depth $\left(\mathrm{PRD}_{\mathrm{AIR}}\right)$ but increases the increment of the rut depth $\left(\mathrm{WTS}_{\mathrm{AIR}}\right.$ ) of some variants. Nevertheless, it is necessary to emphasize that the values are significantly below the limits required by the standard.

For the $\mathrm{AC}_{\mathrm{bin}} 22+$ mixture containing $30 \% \mathrm{RA}$, all the variants tested fulfill the standard criteria. In this test, it is evident that the mixture with CRMB 25/55-60 V in $\mathrm{AC}_{\text {bin }} 22+$ with $30 \% \mathrm{RA}$ exhibits better rutting resistance in terms of $\mathrm{PRD}_{\text {air }}, \mathrm{WTS}_{\text {air }}$ and the rutting depth compared to the CRMB 25/55-60 V in $\mathrm{AC}_{\text {bin }} 16+$ with $40 \%$ RA. This may be due to the coarse size of the virgin aggregates and the content of the reclaimed asphalt which stiffens the asphalt mixture. In addition, the use of wax does not have any extra effect in improving the resistance against the permanent deformation; instead, it is worse compared to the virgin paving grade binder (70/100).

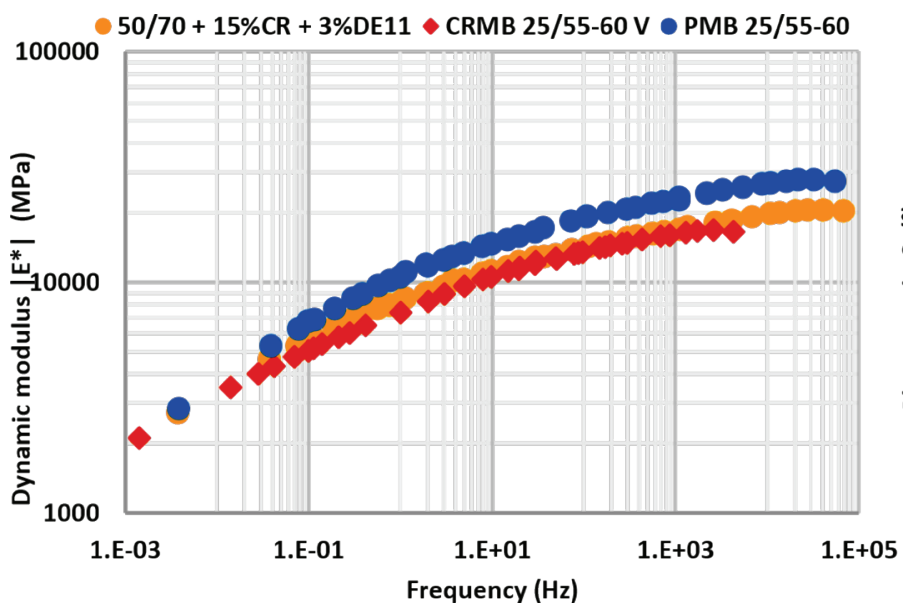

\section{6 Dynamic modulus as determined by a 4-point bending test}

The dynamic modulus was determined with a four-point bending test method (4PB-PR) according to EN 12697-26. Test beam specimen with dimensions of a 50 × 50 x $400 \mathrm{~mm}$ were cut from slabs. These slabs were produced using segmental compactor in accordance with EN 12697-33. The test was conducted in a controlled strain mode with the desired deformation of 50 microstrains. The measurements were performed at temperatures of $0^{\circ} \mathrm{C}, 10^{\circ} \mathrm{C}, 20^{\circ} \mathrm{C}$, and $30^{\circ} \mathrm{C}$. For each temperature tested the measurements were performed at 11 selected test frequencies $(50$, $30,20,15,10,8,5,3,2,1$ and $0.1 \mathrm{~Hz}$ ).

Based on the values of the complex modulus set at various temperatures and frequencies, it is possible to construct a socalled master curve. The master curve is the most comprehensive way to analyze the deformation behavior of a bituminous mix under different conditions. Using the principle of time-temperature superposition, the data at different temperatures are shifted with respect to the time until the isotherm curves are merged together into one smooth curve. This principle was mainly adopted in order to analyze the mixture properties in a broader condition range in accordance with the tested and specified conditions. The bellow master curves were created by a horizontal shifting of the experimental data and while setting a reference temperature, which in this case was $20^{\circ} \mathrm{C}$. In this test, only three mixtures were tested, i.e., the variant with $50 / 70+15 \% \mathrm{CR}+3 \% \mathrm{DE} 11$, CRMB $25 / 55$ $60 \mathrm{~V}$, and PMB 25/55-60.

It is expected that $\left|\mathrm{E}^{*}\right|$ increases with increases of frequency and decreases in the temperature and that the phase angle decreases with an increase in frequency and increase of the temperature.

Fig. 13 clearly shows that the effect of the WMA additive (DE11) and the crumb rubber modified bitumen CRMB 25/55-60 $\mathrm{V}$ in the asphalt mixtures is relatively similar since the shape of their dynamic master curves tend to converge to each other in the entire range of the test temperatures and frequencies. However, they are both significantly different from the shape of the complex modulus master curve of the variant with the PMB, which shows greater values. It is necessary to emphasize that the higher $\left|\mathrm{E}^{*}\right|$ is, the better the mixture would perform in resistance to rutting. Consequently, the PMB has a better rutting resistance compared to the WMA additive and CRMB 25/55-60 V, which confirms the results from the resistance to permanent deformation test.

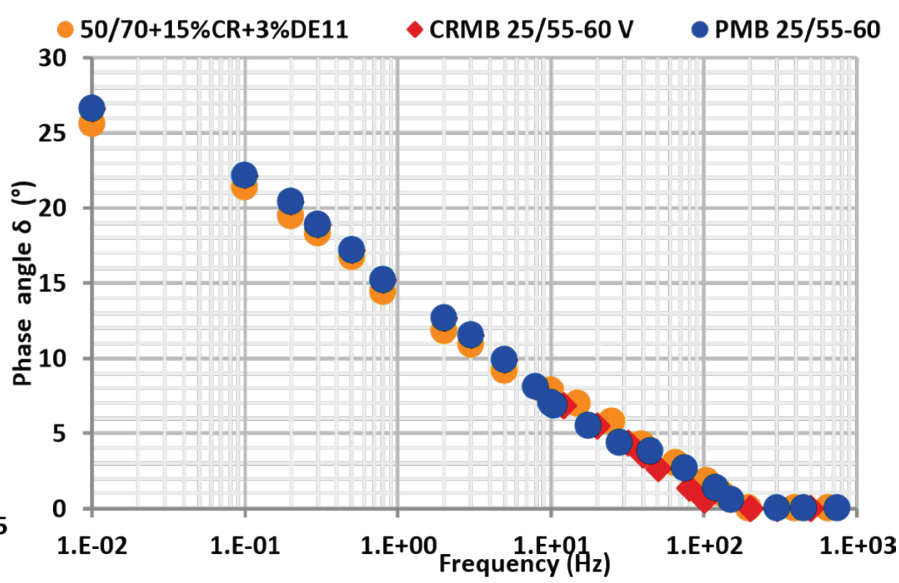

Fig. 13 Master curves of the dynamic modulus (left) and phase angle (right) of the $A C_{b i n} 16+$ mix with $40 \%$ RA (reference temperature at $20^{\circ} \mathrm{C}$ ) 

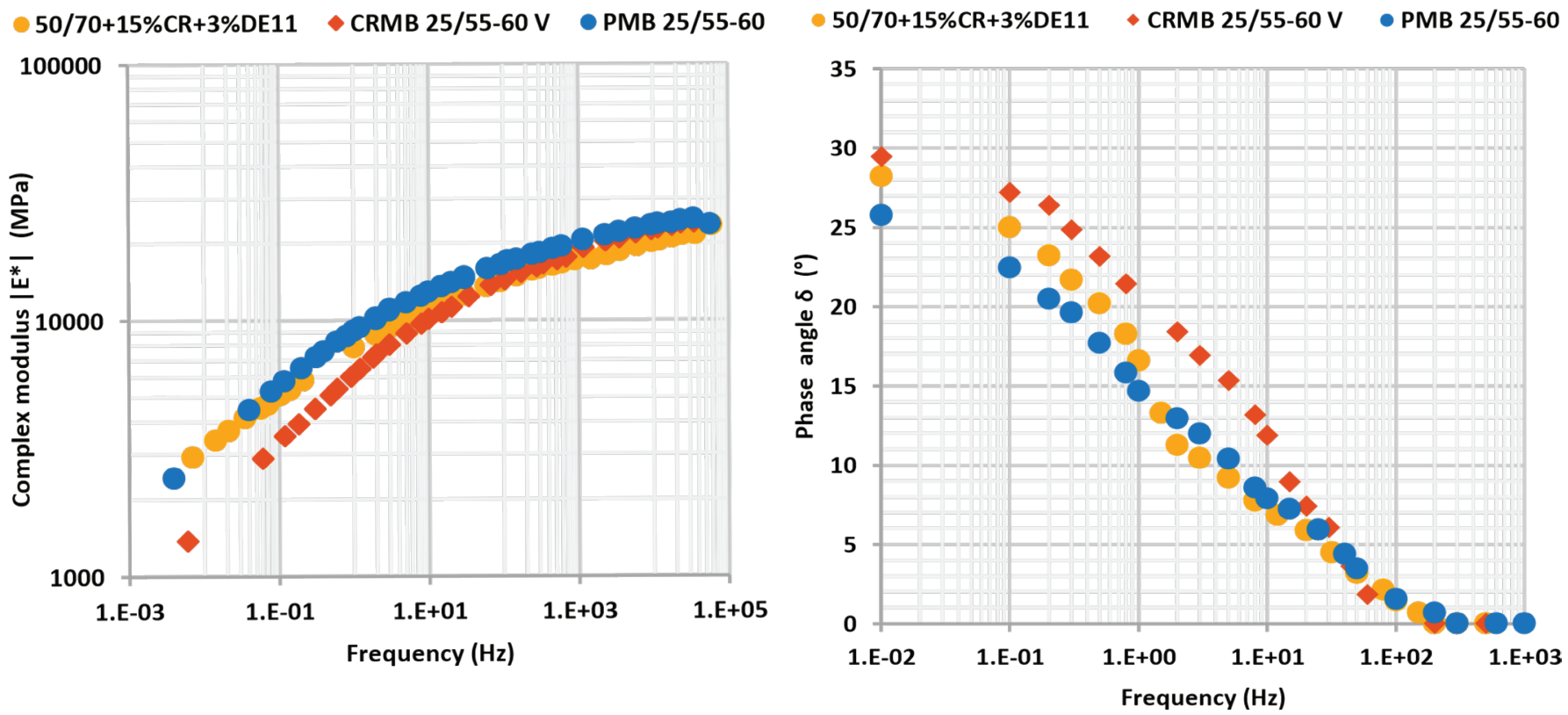

Fig. 14 Master curves of the dynamic modulus (left) and phase angle (right) of the $A C_{\text {bin }} 22+$ mix with $30 \%$ RA (reference temperature $20^{\circ} \mathrm{C}$ )

At low temperature and high frequencies, the phase angle master curves for all the mixtures overlap and reach the zero value; thus, the three mixtures have the same behavior in this range of temperatures. At low frequencies, the $\delta$ master curves of the mixtures with CRMB and PMB were merged and have better values than the variant with the WMA additive. However, at the middle temperatures and frequencies, the variant with DE11 showed better effects.

The mixture with PMB 25/55-60 is the most viscous mixture since its spectrum shows the highest values of the dynamic modulus. Whereas, at high temperatures and low frequencies, the latter showed the same values as the mixture with PMB, while at low frequencies, the $\left|E^{*}\right|$ master curve of this mixture merged with the one containing CRMB 25/55-60 V. This progression of the master curve indicates that for this type of asphalt mix, the variant with CRMB 25/55-60 V has the highest temperature sensitivity.

It is notable that the addition of PMB 25/55-60 showed better results in terms of the dynamic modulus in $\mathrm{AC}_{\text {bin }} 16+$ with $40 \%$ $\mathrm{RA}$ than in the case of $\mathrm{AC}_{\mathrm{bin}} 22+$ mix with $30 \% \mathrm{RA}$. This could be explained by the good interaction of the PMB with fine aggregates. On the other hand, the CRMB 25/55-60 V and the binder $50 / 70+15 \% \mathrm{CR}+3 \%$ DE11 exhibit better a dynamic modulus in $\mathrm{AC}_{\text {bin }} 22+$ with $30 \% \mathrm{RA}$ than in $\mathrm{AC}_{\text {bin }} 16+$ with $40 \% \mathrm{RA}$. This proves that the binders modified by crumb rubber might interact better with coarse aggregates.

Similarly to the $\mathrm{AC}_{\text {bin }} 16+$ with $40 \% \mathrm{RA}$, the phase angle master curves for the three mixtures tend to merge together to the zero value around the high frequencies. Hence, at the remaining range of temperatures and frequencies, the variant with the CRMB V shows the most viscosity. On the other hand, as is shown in Fig. 14, at low frequencies, the addition of the WMA additive showed better values compared to the PMB variant. Whereas, at medium temperatures, the curve of the variant with the PMB takes over and showed slightly better values.

\section{SUMMARY}

The aim of this research study was to compare different solutions for asphalt mixtures with elevated RA contents and different
CR-based bituminous binders. The project involved 9 different laboratory mix variants of typical concrete used in a binder course $\left(\mathrm{AC}_{\text {bin }} 16^{+}\right)$and 5 mix variants for the binder course $\left(\mathrm{AC}_{\text {bin }} 22+\right)$. The mixtures differed in the bituminous binder used from a paving grade binder through conventional PMB to crumb rubber-modified binders. The used CRMBs were either a commercialized kind or modified by a warm mix asphalt additive following the idea of improving workability and lowering the manufacturing or paving temperatures. All the mixtures from the same course $\left(\mathrm{AC}_{\mathrm{bin}} 16+\right.$ and $\mathrm{AC}_{\text {bin }} 22+$ ) were manufactured according to the same reference mix design; only the variants with the CRMB included a $0.3 \%$ higher amount of bituminous binder.

Some of the mix modifications behaved as expected, but some of the test results were surprising. For example, it was assumed that softer bituminous binders would have a positive effect on workability, which was not the case with the paving grade bitumen (70/100). Hence, most of the modified binders have lowered the air void contents except for the CRMB V and WMA additives which showed negative effects. On the other hand, the addition of the WMA additive (DE11) showed better results while decreasing the compacting temperature (from $160^{\circ} \mathrm{C}$ to $150^{\circ} \mathrm{C}$ ).

Along the binder course mixture, $\mathrm{AC}_{\text {bin }} 16+$, the use of $15 \%$ $\mathrm{CR}$ in the mixture caused a significant increase in the strength properties, i.e., the stiffness and indirect tensile strength. This mixture showed a good resistance not only to water but also to climatic changes. On the other hand, the addition of polyethylene wax (DE11) showed an opposite effect and the worst stiffness modulus.

The water and water+freeze susceptibility of the CR variants was better in comparison with the PMB variant except for the variant with CRMB V. It is necessary to emphasize that the variant with CRMB V did not fulfill the standard criterion of ITS EN, and the variants with PMB were very close to this limit.

The SCB test was performed at two different temperatures, and both test results showed that the addition of CRMB V had the best resistance to thermal-induced and fatigue cracking. But, here again, the addition of the WMA additive showed a decrease in fracture characteristics. 
As for the rutting test, all the modified binders improved the average rut depth of $1.8 \%$ for the variant with $15 \% \mathrm{CR}, 2.1 \%$ for both variants with $\mathrm{PMB}$ and DE11, and $2.5 \%$ for the variant with CRMB V. These results are confirmed by the dynamic modulus master curve. It is seen that at a high temperature and low frequencies, the variants with the PMB, DE11 and CRMB V were behaving the same. Yet, at high frequencies, the shape of the dynamic master curve of the mixture with PMB presented better values and thus, better rutting resistance.

Similarly, the use of CR in the mixture of the binder course $\mathrm{AC}_{\mathrm{bin}} 22+$, showed a significant increase in strength properties. Hence, these mixtures did not achieve any improvement in terms of water and to susceptibility freezing compared with the PMB variant.

The low temperature fracture properties also exhibited that the mixtures with CRMB 25/55-60 V perform better than the mixtures with the WMA additive or PMB; thus they show good resistance to frost cracking and crack propagation and initiation in the low temperature range. On the other hand, the variant with PMB was assumed to have a better resistance to fatigue cracking and crack propagation and initiation at higher temperatures $\left(25^{\circ} \mathrm{C}\right)$.
Finally, the rutting test and dynamic modulus test revealed that the variant with PMB has the best results in rutting resistance, which in general was expected.

A comparison of the different varieties of crumb rubber-modified bituminous binder shows that the CRMB 25/55-60 V and bitumen with $15 \% \mathrm{CR}$ accomplished good results for both binder courses, whilst the use and effects of the WMA additive is still unclear. The additive improved some of the properties, but significantly worsened for example, the air void contents, stiffness and fracture properties. It is probably necessary to further research the interaction of these "chemical" components, for example, by functional (performance-based) test characteristics of crumb rubber-modified binders.

\section{Acknowledgments}

This paper was elaborated within the activities of Project No. GA18-13830S supported by The Czech Science Foundation (GACR).

\section{REFERENCES}

Behroozikhah, A. - Morafa, S.H. (2017). Investigation of fatigue cracks on RA mixtures containing Sasobit and crumb rubber based on fracture energy. Construction and Building Materials, 526-532.

Farshad Saberi, K. - Fakhri, M. - Azami, A. (2017). Evaluation of warm mix asphalt mixtures containing reclaimed asphalt pavement and crumb rubber. Journal of Cleaner Production, 165, 1125-1132.

Mohammad, L.N. - Cooper, S.B. - King, B. - Raghavendra, A. (2013). Characterization of HMA Mixtures Containing High Reclaimed Asphalt Pavement Content With Crumb Rubber Additives. Louisiana Transportation Research Center.
Rodríguez-Alloza, A.M. - Gallego, J. - Pérez, I. (2013). Study of the effect of four warm mix asphalt additives on bitumen modified with $15 \%$ crumb rubber. Construction and Building Materials, 43, 300-308.

Singh,D. - Sawant, D. - Xiao, F. (2017). High and intermediate temperature performance evaluation of crumb rubber modified binders with RA. Transportation Geotechnics, 10, 13-21.

Xiao, F. - Amirkhanian, S.N. - Shen, J. - Putman, B. (2009). Influences of crumb rubber size and type on reclaimed asphalt pavement (RA) mixtures. Construction and Building Materials, 23(12), 1028-1034. 